\title{
RUMO A UMA GLOBALIZAÇÃO DA MEMÓRIA*
}

\author{
VERS UNE MONDIALISATION DE LA MEMOIRE
}

Henry Rousso**

rousso@ihtp.cnrs.fr

RESUMO: Em contextos diferentes e apesar da diversidade das heranças históricas, há trinta anos a relação com o passado tende a se unificar, a se "globalizar ", a suscitar formas de representações coletivas e de ações públicas que, pelo menos aparentemente, se assemelham cada vez mais de uma ponta a outra do planeta. Isto pode ser observado pela evidenciação de temporalidades comparáveis na cronologia da memória de episódios traumáticos, e mais ainda pela emergência de um novo espaço público mundial que contribui para unificação do lugar respectivo do passado, do presente e do futuro, insistindo no papel da recordação. Entre outros aspectos, esta "globalização " se caracteriza pela crescente importância que a figura da vítima adquire, que testemunha, ainda que tardiamente, seus sofrimentos, especialmente perante cortes de justiça ou comissões de verdade e de reconciliação e, de um modo geral, por ações da sociedade civil em luta para que a tomada de consciência em relação aos crimes do passado resultem em formas de reconhecimento e de reparação públicas sem levar em conta o tempo que passou.

PalaVRAS-ChaVE: Memória; Crimes de massa; Testemunho.

RESUMÉ: Dans des contextes différents et malgré la diversité des héritages historiques, le rapport au passé tend depuis trente ans à s'unifier, à se " mondialiser ", à susciter des formes de représentations collectives et d'actions publiques qui, au moins en apparence, se ressemblent de plus en plus d'un bout à

\footnotetext{
* Uma primeira versão deste texto foi publicada como introdução ao número especial : "Vers une mondialisation de la mémoire ", in dossiê Mémoires Europe-Asie ", Vingtième siècle [Paris, Presses de Sc. Po], 94, abril-junho 2007, pp. 3-10. Tradução de Fábio Ferreira de Almeida.

** Pesquisador do CNRS e do Instituto de História do Tempo Presente, em Paris.

Recebido em 17 de outubro de 2013 Aprovado em 29 de novembro de 2013
} 
l'autre de la planète. Cela peut s'observer par la mise en évidence de temporalités comparables dans la chronologie de la mémoire d'épisodes traumatiques, et plus encore par l'émergence d'un nouvel espace public mondial qui contribue à unifier la place respective du passé, du présent et du futur, en insistant sur le rôle du souvenir. Cette "mondialisation " s'est caractérisée entre autres par une montée en puissance de la figure de la victime, celle qui témoigne, même tardivement, de ses souffrances passées, notamment devant des cours de justice ou des commissions de vérité et de réconciliation, et d'une manière générale par des actions de la société civile luttant pour que la prise de conscience des crimes du passé débouche sur des formes de reconnaissance et de réparation publiques sans tenir compte du temps écoulé.

MoTS-CLÉS: Mémoire; Crimes de masse; Témoignage.

Uma constatação parece agora se impor de maneira inequívoca: em todas as partes do mundo, apesar dos diferentes contextos políticos ou culturais, apesar ainda da extrema diversidade das heranças históricas, a relação com o passado não apenas conheceu importantes mudanças estruturais no último terço do século XX e início do século XXI, mas tende a unificar-se, a "globalizar-se ", a suscitar formas de representações coletivas e de ações públicas que, pelo menos aparentemente, são cada vez mais semelhantes. Observada em larga escala, esta constatação não se limita nem à recordação de alguns acontecimentos recentes, ainda que eles tenham sido excepcionais, como o Holocausto, nem a um espaço circunstanciado como o "mundo ocidental". Ela diz respeito à escrita do passado nacional em inúmeros países e se manifesta igualmente, há alguns anos, como aquilo que principalmente está em jogo em termos de política em uma escala regional como, por exemplo, a da União Europeia, ou em uma escala global, particularmente no seio da Organização das Nações Unidas. Este fenômeno se desenvolve de acordo com eventos históricos muito distintos por sua natureza, temporalidade ou espaço: as lembranças obsedantes do nazismo por toda Europa; as polêmicas recorrentes sobre os efeitos da Segunda Guerra Mundial e da Hist. R., Goiânia, v. 19, n. 1, p. 265-279, jan./abr. 2014 
ocupação japonesa no Extremo Oriente; a longa memória da escravidão na América do Norte ou, na França, a da colonização na África; os agitados debates sobre a herança da ditadura militar na América do Sul ou as sequelas físicas e morais dos grandes massacres de massa por todos os cinco continentes. Assiste-se, assim, a um mesmo, para não dizer homogêneo, movimento planetário de reativação do passado, e podem-se observar, simultaneamente, numerosas semelhanças nas expectativas da opinião pública e nas políticas empregadas para dar um "justo" lugar à história e à memória em contextos aparentemente muito distantes uns dos outros.

Esta evolução fornece hoje matéria abundante aos cientistas políticos, aos sociólogos, aos filósofos, aos historiadores. Os questionamentos podem ser modulados em registros teóricos ou empíricos os mais diversos: análise de usos, de representações e de "políticas do passado" ${ }^{1}$, trabalhos sobre a "gestão do passado " (Vergangenheitsbewältigung) ou o "dever da memória", sobre o patrimônio e a patrimonialização ou ainda a "cultura da lembrança" (Erinnerungskultur) ${ }^{2}$, sobre a justiça "transicional" ou "restaurativa", que repousa sobre interpretações normativas do passado próximo ${ }^{3}$, enfim, sobre os fins de guerra, de guerra civil e de ditadura. Todos estes trabalhos abordam, explicitamente ou não, questões concernentes a uma possível mudança de "regime de historicidade" ${ }^{4}$. Por "regime de historicidade", entendemos uma evolução profunda da natureza, do lugar, do papel e dos efeitos que o passado tem sobre o presente das sociedades, num dado lugar e momento - aqui, ao final do século XX - e precisamente numa escala que se tem que determinar.

O presente artigo propõe, com efeito, a hipótese de que esta mudança não diz respeito apenas à civilização europeia, mas atinge um espaço bem mais amplo, global sem dúvida, com todas as precauções que o uso deste termo implica atualmente. Em sua primeira versão, ele figurava como introdução a um número especial da revista francesa Vingtième 
siècle, número dedicado à análise comparada da memória de conflitos internos ou externos na Europa e na Ásia, concentrando-se particularmente no estabelecimento de um paralelo da gestão longa do passado nazista e com as querelas reativadas na "guerra dos Quinze Anos" (1931-1945) na Ásia oriental. ${ }^{5}$ A escolha dos termos da comparação repousava, primeiramente, sobre uma proximidade evidente: a Segunda Guerra Mundial, no sentido amplo do termo, forma não apenas uma matriz histórica comum aos dois continentes, mas constituiu, tanto na Ásia como na Europa, um acontecimento central na história recente cujos efeitos se fazem ainda sentir, não apenas no plano da memória, mas também num plano político e social, e mais ainda no plano das relações regionais e internacionais. Contudo, mesmo que isso pudesse naturalmente explicar certas semelhanças na gestão do passado, as diferenças de situação na história respectiva do pós-guerra na Europa e na Ásia, especialmente na Alemanha e no Japão, e mais ainda as diferenças de cultura, particularmente em tudo o que concerne às relações entre tradição e modernidade, eram suficientemente grandes para que as diferenças se sobrepusessem às semelhanças. Ora, tal não é o caso se levarmos em conta os diferentes textos publicados no número especial que mostrava, antes, grandes semelhanças na gestão e nos usos do passado recente, como se as singularidades nacionais ou continentais aí não fossem plenamente atuantes. Além do mais, o número especial levava igualmente em conta processos históricos de outra natureza, como a memória do comunismo ou a de conflitos localizados, como os da Irlanda do Norte, o que não permitia estender o campo de comparação até os fenômenos da memória. Assim é que este texto nasceu, interrogando algumas explicações de possíveis pontos comuns, de transferências e empréstimos recíprocos possíveis na atenção dispensada às recordações e na gestão do passado em uma escala global. 
AS MODALIDADES COMUNS DE GESTÃO DO PASSADO

Duas séries de elementos permitem destrinchar ad minima a ideia de uma globalização das relações com o passado: uma sobressai do realce dado às temporalidades comparáveis na cronologia da lembrança de episódios traumáticos, a outra, sobre a qual insistiremos mais aqui, da emergência de um novo espaço público mundial.

Se observarmos a evolução da memória e das representações de eventos como o Holocausto, a Segunda Guerra Mundial, as guerras coloniais dos anos 1950-1960, e até de eventos ou de processos mais antigos como a escravidão, perceberemos que existem semelhanças entre eles. O fim imediato do acontecimento traumático - fim de genocídio ou de ditadura - traduz-se, em geral, pelo desenvolvimento de um intenso debate sobre o número e a natureza das vítimas, sobre o destino a ser dado a seus carrascos, sobre a possibilidade ou não de julgá-los ou de simplesmente afastá-los, de destituí-los das funções que ocupavam no aparelho de Estado, no exército, na polícia, etc. Também é o momento em que se estabelecem as primeiras formas de comemoração, erigem-se os primeiros monumentos, são decididas as primeiras formas de reparação e de compensação, à maneira do que ocorreu quando da queda do III Reich na Europa. Em seguida, por diferentes modalidades e depois de um período que pode variar de acordo com o caso, começa um período durante o qual a escolha do esquecimento, da anistia, do silêncio sobre os crimes do passado parece preponderar numa parte da opinião face às necessidades da reconstrução física e moral do país e às da reconciliação da unidade nacionais. Depois, num terceiro momento, às vezes muito tempo depois, como no caso da lembrança do Holocausto e das guerras coloniais (como a guerra da Argélia, na França), outras vezes muito mais rápido, vê-se despontar, ao contrário, o desejo de reabrir a página ou de não virá-la, de manter os processos judiciais em curso, continuar o "trabalho de memória" e de vigilância face à presença possível de antigos criminosos ou 
responsáveis entre as elites que estão no poder. Esta última fase pode constituir uma verdadeira anamnese, como foi o caso na Europa ocidental na virada dos anos 1970, em relação ao passado nazista. Ela pode desembocar numa fase de "hiperamnésia", no sentido que este termo assume em Paul Ricoeur, isto é, de uma cristalização de um conflito não resolvido, em favor do qual o trabalho coletivo de memória não encontra seu ponto de chegada e não consegue apaziguar o ressentimento legítimo das vítimas e de seus descendentes. ${ }^{6}$ Foi este o caso do Holocausto, apesar das políticas de reparação em grande escala durante os anos 1990-2000 na Alemanha, na França, nos Estados Unidos; é o caso a fortiori nos conflitos para os quais não há processo algum, nem julgamento, portanto, nenhuma identificação precisa dos fatos, das vítimas, das reparações possíveis.

Com isso, a novidade não se liga tanto à possível repetição desta sequência ternária - luto infindo, amnésia, anamnese - em contextos historicamente distintos quanto ao fato de que converge, no final do século $\mathrm{XX}$, uma tendência, um desejo geral, quaisquer que sejam os lugares e os episódios históricos envolvidos, antigos ou recentes, desta lembrança de crimes do passado, de repará-los, de julgá-los, de impedir toda forma de esquecimento. Que este desejo tenha sido parcial ou completamente saciado é um outro caso, o que conta aqui é esta convergência na visão de um passado que não deve passar, que deve permanecer presente, como uma sentinela para o futuro.

Este novo regime de historicidade que valoriza a lembrança, que elabora o tempo histórico privilegiando a visão do presente, desenvolve-se lado a lado com a emergência de um novo espaço público global que contribui para mudar nossa visão da História. Em primeiro lugar, de uma ponta à outra do planeta, os Estados estão, hoje, confrontados com visões concorrentes e alternativas do passado que colocam em questão a tradicional dominação da história nacional. Hipótese muitas vezes defendida na França, especialmente após as querelas memorialísticas de 2005-2006, aí estaria uma consequência do enfraquecimento do 
sentimento nacional e dos progressos do "comunitarismo", dentre outros fatores culturais. ${ }^{7}$ Se não se pode dizer que o argumento seja impertinente da perspectiva estritamente francesa e, sem dúvida, no contexto de outras nações europeias, seu impacto fica particularmente enfraquecido a partir do momento em que nos situamos numa escala não exclusivamente nacional, a única atualmente possível para compreender os fenômenos de memória. ${ }^{8}$ Na realidade, a novidade aqui está menos ligada à existência de narrativas históricas ou de memórias singulares fundadas na língua, na etnia, na religião ou uma experiência de comunitariedade compartilhada que sempre foram uma realidade, especialmente nas áreas em que os sistemas políticos e sociais conferem um lugar importante, quando não de direitos equivalentes, às minorias - que à formação de um novo espaço público no plano nacional, regional (especialmente europeu) e mundial. Este espaço se caracteriza por uma crescente escuta de grupos que propõem narrações históricas que tendem a rejeitar não apenas a história nacional, mas também parte importante da história científica, acadêmica, suspeita, no melhor dos casos, de cegueira quanto ao destino dos "esquecidos" da História ou, no pior dos casos, de ser uma "história oficial" produtora de "tabus", quando não de contribuir para a manutenção de um sistema de dominação. Esta tomada da palavra cada vez mais manifesta tem por efeito abolir as fronteiras tradicionais entre o discurso do cientista, do político, do ator, do militante, e a abertura para uma pluralidade mais ou menos controlada das interpretações do passado, cujo impacto repousa menos sobre a validade e veracidade dos propósitos emitidos que sobre a capacidade dos atores em se fazerem ouvir, por vezes em se fazerem inscrever numa lógica de "escandalização", isto é, de provocação deliberada, destinada a "fazer barulho", em particular graças à rapidez e à reatividade das novas tecnologias da informação. ${ }^{9}$ Este procedimento foi largamente utilizado nos quadros da memória do Holocausto e ainda hoje o é em outros domínios, como a lembrança da escravidão ou da colonização. 
Neste sentido, as modalidades do debate sobre a história (ou sobre a memória) não se distinguem fundamentalmente daquelas que se podem observar acerca de outros temas, como o da saúde, do clima ou do meio-ambiente, que, do mesmo modo, colocam em jogo inúmeros conflitos de interesse entre enunciados científicos, emoções populares e políticas públicas. Uma das consequências paradoxais disso foi a vigorosa escalada, em todo caso a de maior visibilidade, de toda sorte de "revisionismos", sejam eles legítimos, isto é, inscritos em um espaço de discussão comum com a história ortodoxa e apresentando-se quase sempre como "contrahistórias ", vistas de baixo ou de cima, sejam eles perversos, como o negacionismo antissemita que tem por objetivo explícito levar a erros, mas que se aproveitou do clima geral de questionamento da história recente da Europa, nos anos 1970-1980, para precipitar-se pela fresta.

Este novo espaço público se caracteriza, em segundo lugar, pelo acréscimo de poder da figura da vítima, e da vítima que testemunha, ainda que tardiamente e em especial perante cortes de justiça ou comissões de verdade e de conciliação, os sofrimentos que lhe foram infringidos: neste sentido, a « era do testemunho » foi primeiramente a da vítima e começou, não com o processo Eichmann, em 1961, mas com o fim da Primeira Guerra Mundial, primeira experiência de violência extrema de massa que levou a milhares de testemunhos febris de todo e qualquer anônimo. ${ }^{10}$ Isso caminha lado a lado com o aumento progressivo, para não dizer invasivo, do espaço que as lembranças de crimes do passado ocupam nas sociedades contemporâneas, por vezes reduzindo a História ou antes o que é digno de ser rememorado em nosso presente a uma sucessão de delitos e de massacres. É uma das razões que explicam que a " memória » tenha se tornado um valor positivo quase universal, uma tradição reinventada que se opõe ao "esquecimento ", tornado, este, um valor negativo: pode-se esquecer um bem sem grandes consequências, mas esquecer um crime seria cometê-lo uma segunda vez. Este credo evidente, quase naturalizado em nossos dias, funda contemporaneamente inúmeras 
ações de memória e, ainda que seja discutível no plano ético, político ou jurídico, e que em nada constitua uma constante na longa história de saídas de guerras: ao contrário, o esquecimento, a anistia, o perdão, foram, até recentemente, mais ou menos até por volta dos anos 1970, as principais estratégias das sociedades a permitir que se levasse a um termo realista conflitos externos ou internos, notadamente nas áreas dominadas pela cultura judaico-cristã. Acrescente-se que, antes de tudo, o processo dizia respeito a acontecimentos recentes, e especificamente às sequelas da Segunda Guerra Mundial ou dos sistemas coloniais dos séculos XIX e XX, mas que, doravante, ele se estende a episódios cujas origens remontam a uma distância no tempo cada vez maior, como mostram os vivos debates acerca da memória da escravidão. Nada mais se opõe a que todo episódio da história humana possa constituir-se como objeto, num momento ou outro, de uma reivindicação ou de uma política memorialística: estamos com isso numa das mais nítidas manifestações do "presentismo ", manifestação de um desvanecimento imaginário das fronteiras entre o presente e o passado, o que faz dos contemporâneos os contabilistas, os juízes e os expiadores de todos os crimes cometidos por "nossos" antepassados. Esta evolução criou, de fato, a ideia de que existe uma responsabilidade temporal coletiva que tende para imprescritibilidade geral, não mais tendo as ações humanas, pelo menos as mais nefastas, o direito de adentrar à categoria de passado concluso.

A existência de um novo espaço público traduz-se, em terceiro lugar, por novas formas de ações políticas. Quase por toda parte, em variados graus e sob formas evidentemente diversificadas, podem-se observar aspirações convergentes levadas por formas similares de ações públicas e de mobilizações coletivas que podem ser desenvolvidas- segundo um mesmo modelo, especialmente se se trata de considerar uma "história criminal". Elas se inscrevem nesta fase de anamnese descrita acima:

Primeiro momento: a necessidade de uma tomada de consciência dos " erros » e dos "crimes » do passado, termos que podem 
abranger um amplo leque de situações históricas que os contemporâneos são convidados a enfrentar. É durante esta fase que as associações de vítimas e suas modalidades de ação desempenham um papel essencial, dado que o que está em jogo é criar ou fazer emergir novamente a sorte deles como um problema público importante, que pede análise e solução;

Segundo momento: a exigência de um reconhecimento de vítimas assim identificadas, particularmente pela vontade de inscrever a remissão ao sofrimento delas numa narrativa histórica coletiva renovada, e até revisada, nela incluída, segundo a necessidade, através de uma qualificação (ou uma requalificação) penal de fatos acabados, como ocorreu nos processos tardios contra criminosos de guerra nazistas ou no caso das "leis memorialísticas na França", que permitiram, por exemplo, qualificar retroativamente a escravidão e o tráfico transatlântico ocidental - e unicamente este - como "crimes contra a humanidade";

Terceiro momento: a eventual concessão de formas diversas de reparação a danos sofridos por meio de ações judiciais nacionais ou internacionais, penais ou civis, por meio de políticas de indenização, pela instauração de rituais tradicionais (construção de monumentos, criação de comemorações) ou novas (as comissões de reconciliação na América do Sul ou na África, os textos jurídicos reinterpretando o passado de acordo com as normas do presente). O leque de políticas públicas do passado, de resto, não cessa de se ampliar desde alguns anos e esta interpelação mais forte e sistemática dos poderes públicos (em sistemas democráticos e abertos) resulta cada vez mais numa zelosa escuta, principalmente nos países europeus, podendo a recusa em aquiescer ao imperioso «dever de memória " constituir doravante um empecilho mais ou menos constrangedor para as elites políticas. Além disso, estas demandas e estas ações públicas não raro trocam de lugar, em uma escala supranacional, com organizações não governamentais ou instituições internacionais, como no caso emblemático do processo Pinochet e em quase todos os processos paramentados de uma dimensão penal. 


\section{ELEMENTOS DE EXPLICAÇÕES}

Se admitirmos estas proximidades, estas concomitâncias, estes pontos em comum, e não esquecendo de que a constatação operada aqui resulta de uma observação por um foco bem aberto, coloca-se, então, uma questão simples, mas persistente: com explicar essa convergência nas relações que as sociedades contemporâneas mantêm com o passado? Poderia convocar aqui explicações de ordem estrutural sobre a gestão do luto, a clínica de traumas, a relação entre psicologia individual e imaginário coletivo. ${ }^{11}$ Sem que isso constitua uma explicação unívoca, vou me ater a um registro mais estritamente histórico, a saber: a existência de uma conjuntura particular.

A globalização de fenômenos culturais, a existência de lugares e de repertórios de ações em nível transnacional ou internacional, especialmente em matéria judiciária, a uniformização - relativa - de certas práticas políticas (a transparência democrática), de certos valores (a defesa dos direitos humanos), de certas preocupações sociais (a compaixão), podem explicar a crença numa ação reparatória e retroativa a respeito do passado. Esta conjuntura recebe um realce ainda maior pelos efeitos de dois acontecimentos de natureza distinta.

O primeiro é, evidentemente, o extermínio dos judeus pelos nazistas, que é um crime cuja natureza e amplitude não têm precedentes na história, e que deu origem, após 1945, a formas, também elas sem precedentes, de gestão do passado, termo que também se inscreve no contexto pós-Auschwitz. Estas se desenvolveram inicialmente no âmbito da República Federal Alemã que forneceu o modelo da Vergangenheitsbewältigung, cuja história, edificante em certa medida, é atualmente questionada, como testemunha o percurso e a recente polêmica em torno de escritor Günter Grass. A memória do Holocausto espalhou-se em seguida pelos países vizinhos, na sequência ou paralelamente a conflitos de memória autóctones (como a questão de 
Vichy, na França), em seguida em escala europeia e internacional. A memória do Holocausto é, sem dúvida, até mesmo um elemento central na importância cada vez maior da noção de memória nos anos 1970. A partir de então, e por um processo que nada de escrito poderia antecipar, o combate de um punhado de vítimas pelo reconhecimento e, em seguida, pela reparação parcial dos crimes cometidos pelos nazistas contra os judeus, assumiu uma amplitude sem precedentes até tornar-se o paradigma memorialístico por excelência. Sejam as formas da ação coletiva em favor da memória, seja a construção de problemas públicos ligados a interpretações do passado, ou ainda a sintonia de repertórios específicos de ação fundados, por exemplo, na possibilidade de reparações judiciais, simbólicas ou financeiras, a gestão recente desta memória suscitou, a um só tempo, formas de desejo, mimetismo, concorrência, tendo igualmente contribuído para a globalização do problema. ${ }^{12}$

O segundo acontecimento foi a queda do muro de Berlim, ainda que seja preciso evitar transformar este acontecimento na explicação obrigatória de todo fenômeno histórico recente. A queda do comunismo e o fim da Guerra Fria significaram formas de democratização na Europa central e oriental e precipitaram, sem dúvida, o desaparecimento duradouro de outros sistemas ditatoriais na América Latina, ou do apartheid na África do Sul, levando vários países a interrogarem-se a respeito da gestão imediata, ou a médio prazo, de seu passado numa escala inusitada desde 1945. Não há, contudo, relação sistemática, mesmo após 1989, entre um processo de transição democrática e a emergência de um novo modelo memorialístico. Por um lado, se há uma "memória » que permanece como construída, é a da herança comunista no sentido amplo do termo que constitui até mesmo uma exceção notável ao modelo esboçado aqui. As representações e os usos do passado comunista permanecem ainda espremidos em espaços políticos, geográficos, mentais infinitamente mais restritos que a importância do fenômeno comunista no século XX. Eles até continuam a separar, com uma linha invisível, as 
tradições históricas do Leste e do Oeste da Europa, e disso a dificuldade em fazer emergir na Rússia uma memória do Gulag dá testemunho. Toda a questão é saber se se trata de uma exceção estrutural ou se a atual fase de amnésia relativa vai resultar, como em outros lugares ou em outros tempos, numa anamnese de grande escala, de acordo com o modelo esboçado acima. Por outro lado, os fenômenos de anamnese, de vitimização, de reparação do passado, não são o apanágio exclusivo dos Estados democráticos: eles aparecem, por exemplo, na China que, num contexto, de fato, diferente, apresenta-se inteira como uma vítima esquecida em sua rivalidade com o Japão.

Aliás, há tantas diferenças quanto semelhanças entre a Ásia oriental e a Europa no que concerne à memória da guerra, para retomar este exemplo que foi o ponto de partida de minha reflexão sobre um possível novo regime de historicidade globalizada. As guerras asiáticas da primeira metade do século XX, por exemplo, não podem ser consideradas como terminadas enquanto o segundo conflito mundial para os países europeus finda em 1945 ou, no pior dos casos, em 1989, se adotarmos o ponto de vista de certa historiografia do leste europeu. Em contrapartida, nos dois casos podemos identificar elementos comparáveis. Assim, os debates na Coréia do Sul relativos à amplitude e aos efeitos da colaboração com o invasor japonês, o ressurgimento recente de uma história ocultada, os dilemas postos por uma colaboração duradoura que contribuiu, em parte, para a modernização do país, relembrando a situação de certos países europeus há mais ou menos vinte anos atrás. 0 mesmo se pode dizer dos debates transfronteiriços a respeito da possível e difícil emergência de uma " história partilhada », antídoto aos nacionalismos, cujo modelo explícito permanece o da reconciliação franco-alemã. Em ambos os casos, as semelhanças não se devem apenas à proximidade dos fenômenos históricos em questão - a colaboração com o inimigo em um país ocupado é um problema genérico qualquer que seja a situação histórica - mas 
também ao contexto geral no qual estes debates explodem de modo concomitante e quase simultâneo nos anos 1990.

Ainda que limitado e certamente incompleto, o objetivo deste breve exercício comparativo foi o de incitar a reflexão sobre a história a sair do quadro nacional. Se os historiadores ou outros pesquisadores em ciências sociais têm necessidade de participar plenamente dos debates públicos sobre o passado que não raro têm o caráter nacional limitado, eles não podem se contentar em simplesmente reagir às polêmicas. A maior contribuição que eles podem oferecer está menos na defesa de uma postura, certamente necessária, que no trabalho teórico e empírico, comparativo e pluridisciplinar, sobre isto que é o que está antes de tudo em jogo no século XXI: a evolução incerta, intrigante, e até mesmo inquietante do nossa relação com a história.

NOTAS

1 Esta expressão é tomada do alemão e inscreve-se no debate matricial acerca do passado nazista. Cf. Norbert Frei, Vergangenheitspolitik. Die Anfänge der Bundesrepublik und die NS-Vergangenheit, Münich, Beck, 1996 [trad. anglaise : Adenauer's Germany and the Nazi Past: The Politics of Amnesty and Integration, New York, Perseus Books Group, 2012].

2 Ver especialmente Aleida Assmann, Cultural Memory and Western Civilization: Functions, Media, Archives, Cambridge, Cambridge University Press, 2011.

3 A literatura recente sobre esta questão é abundante: Michel Dobry (dir), Democratic and capitalist transitions in Eastern Europe. Lessons for the social sciences, Dordrecht et Boston, Kluwer, 2000 ; Sandrine Lefranc, Politiques du pardon, Paris, PUF, 2002 e, sob sua coordenação, Après le conflit, la réconciliation ?, Paris, Michel Houdiard éditeur, 2007 ; Jon Elster, Closing the Books. Transitional Justice in Historical Perspective, Cambridge University Press, 2004, e Jon Elster (dir), Retribution and Reparation in the Transition to Democracy, Cambridge University Press, 2006. Ver também o trabalho de referÊncia de Mark Osiel, Mass Atrocity, Collective Memory \& the Law, New Brunswick, Transaction Publ., 1997

Hist. R., Goiânia, v. 19, n. 1, p. 265-279, jan./abr. 2014 
4 Proveniente da antropologia, este conceito foi desenvolvido por François Hartog, Régimes d'historicité. Présentisme et expériences du temps, Paris, Seuil, 2003. Ver também, do mesmo autor: Croire en l'histoire, Paris, Flammarion, 2013.

5 Cf. Ian Buruma, Wages of Guilt: Memories of War in Germany and Japan, New York, Farrar Strauss Giroux, 1994 ; Christoph Cornelissen et alii (dir), Erinnerungskulturen. Deutschland, Italien und Japan seit 1945, Francfort, Fischer, 2003. Sobre a memória no Japão, ver também : Claire Roulière, La mémoire de la Seconde guerre mondiale au Japon, Paris, L'Harmattan, 2004 ; Philip Seaton, Japan's Contested War Memories: The "memory Rifts " in Historical Consciousness of World War, New York, Routledge, 2007 ; Sebastian Conrad, The Quest for the Lost Nation. Writing History in Germany and Japan in the American Century, Berkeley, University of California Press, 2010 [1e ed. : Göttingen, 1999].

6 Cf. Paul Ricœur, La mémoire, I’histoire, l'oubli, Paris, Seuil, 2000.

7 Ver, por exemplo, Jean-Pierre Rioux, La France perd la mémoire, Paris, Perrin, 2006.

8 Cf. Henry Rousso, "History of Memory, Policies of the Past : What For ?", in Konrad Jarausch and Thomas Lindenberger (ed.), Conflicted Memories. Europeanizing Contemporary Histories, New York/London, Berghahn Books, 2007. Cf. également: Małgorzata Pakier and Bo Stråth (ed.), A European Memory. Contested Histories and Politics of Remembrance, New York, Berghahn Books, 2010 ; Muriel Blaive, Christian Gerbel, Thomas Lindenberger (ed.), Clashes in European Memory. The Case of Communist Repression and the Holocaust, StudienVerlag, Vienne, 2011.

9 Sobre este conceito da sociologia da ação coletiva, ver Michel Offerlé, Sociologie des groupes d'intérêt, Paris, Montchrestien, 1998.

10 Ver Annette Wieviorka, L'ère du témoin, Paris, Plon, 1999 e, principalmente, Avishai Margalit, The Ethics of Memory, Cambridge, Harvard University Press, 2004.

11 Sobre este aspecto, que abre para outros horizontes disciplinares, ver, por exemplo Jean-Claude Métraux, Deuils collectifs et création sociale, prefácio de René Kaës. Paris: La Dispute, 2004.

12 Cf. Daniel Levy, Natan Sznaider, The Holocaust in the Global Age, Philadelphie, Temple University Press, 2006 [1e éd. : Francfort, Suhrkampf Verlag, 2001]. 